\title{
Impact of EHR Technology Implementation on Physicians' Job Satisfaction
}

\author{
Navneet Kaur Bajwa \\ Thapar University \\ Harjot Singh \\ Thapar University \\ Kalyan Kumar De \\ Amity University
}

\begin{abstract}
The concept of an electronic health record (EHR) has been the solicitous subject of researchers' discussion in recent times. The impact that a successful implementation of EHRs can have on physicians cannot be overstated. Factors which are critical to successful implementation of EHR systems are commonly known as crucial technology implementation factors (CTIFs). The present study investigates the CTIFs of EHR systems and also their impact on physicians' job satisfaction and characteristics in North Indian multispecialty hospitals. The questionnaire has been distributed to physicians of 12 hospitals that have been using EHR technology. It has been concluded that five CTIFs-organizational support, training, software attributes, acceptance to change, and computer knowledge-play a more important role than that played by other factors. The factors have not been considered separately on the basis of preimplementation scenario and postimplementation phase. The study attempts to analyze the impact of EHR systems on job operational performance of physicians.
\end{abstract}

Keywords: crucial technology implementation factors, EHR, job satisfaction, multispecialty hospitals, physicians, North India

\section{Introduction}

The electronic health record (EHR) is an essential mechanism, even a competitive weapon that can aid in cost-effective and efficient coordination of care services, including secured sharing of patient information among multiple healthcare providers. Today, successful deployment of appropriate information and communication technologies (ICTs), such as an EHR technology, can enhance patient safety as well as quality of care delivery. Yet, it is argued that gatekeepers of a country's healthcare systems, including physicians and other caregivers such as nurses and pharmacists, must also be actively engaged with, and consistently use, the technology to accrue the intended benefits of EHR systems (Ajami \& Bagheri-Tadi, 2013). Simon et al. (2013) added to this the importance of realtime support, preferably provided by peers and super-users.

A key challenge, which underlies the present study, has been filtering out critical variables that may have affected successful implementation of EHR systems within a specific workplace environment

This research was supported by the Lalit Mohan Thapar School of Management, Dera Bassi, Mohali, Punjab, India, and various private corporate hospitals in the North India region. 
and then studying their impact on job satisfaction of physicians. This research seeks to identify crucial technology implementation factors (CTIFs), as perceived by the primary gatekeepers (practicing physicians), which are relevant for accruing the benefits of EHR implementation efforts in hospitals located in North India. The first step in the study was to rationalize key variables and their corresponding constructs, expressing them in specific, relevant and easy-to-measure activities or outcomes. Such efforts were warranted for researchers to quantify meaningfully (and objectively) attempts to implement EHR systems, which may be positively (or negatively) impacted by changes in identified CTIFs (Safdari, Ghazisaedi \& Jebraeily, 2015).

Notwithstanding, implementation of EHRs is a nontrivial process. During implementation, it is of the utmost importance that all relevant information is always available (Ward et al., 2012). It should not be treated as just a trial-and-error activity, given that much research on ICT uses has already been conducted. Unless healthcare professionals consistently utilize EHR system in direct patient care, success of any such implementation cannot be asserted (Kaplan \& Harris-Salamone, 2009; Pare, Sicotte, \& Jacques, 2006). Indeed, failing a timely and nondisruptive roll out of EHR system can often lead to an undesired risk for the healthcare organization (Moukheiber, 2013). Moreover, such a risk can range in magnitude from failure to attain desired benefits (such as improving patient safety or gaining competitive market advantage) to threatening the financial viability of institution.

This study attempts to identify CTIFs that may reduce the likelihood of EHR implementation failure to encourage hospitals to consider focusing on those key variables that require their most urgent attention (Eni \& Tan, 1989). Apart from identifying factors, the study also examines the impact of these factors on job characteristics and satisfaction of physicians. Although this study may be seen as exploratory, its findings may provide insights to help North India hospitals in achieving effective use of electronic records and providing satisfied physicians. The study can also play a role in adding to understanding of technology diffusion by inspiring both small and medium scale hospitals to implement EHRs.

With the rise of healthcare service providers and introduction of information technology, the healthcare market has become more competitive. Consequently, the service providers are required to understand the factors affecting hospital's performance and providing better quality care using EHRs. There is also a need to understand the factors which impact the efficiency of hospitals. The existing literature on Indian healthcare sector has primarily focused on service quality in hospitals and end results of technologies. A limited number of studies have researched the impact of EHR technology implementation on physicians' characteristics as well as satisfaction. Thus, it has become imperative to study these aspects. Therefore, the present study aims to investigate the impact of EHRs, the critical technology implementation factors and its impact on physicians' job characteristics and satisfaction in Indian context. It studies the behavior of physicians after using the technology.

\section{Indian Healthcare Sector}

India has a population of 1.3 billion residing in 29 states and seven union territories, out of which $2.25 \%$ are situated in Punjab, which consists of 22 districts. Healthcare services in India have traditionally been provided by the government. In the early postindependence period, Indian healthcare sector was suffering from a shortage of doctors and nurses, inadequacy of hospitals as well as a lack of medical equipment. In the 1980 s, approximate $30 \%$ decline was witnessed in the use of both urban and rural public healthcare facilities. Of late, this sector has achieved tremendous growth and has been growing faster than it had grown during the last few decades. It is expected to become US $\$ 280$ billion sector by the end of 2020 (Verma \& Khandelwal, 2011). 
Extant literature has been reviewed with special emphasis on understanding available knowledge about EHRs or EHR implementation in a healthcare organizational context. A parsimonious theoretical framework has been highlighted for which the present study is expected to translate a large body of literature on CTIFs to a study in context of hospitals based in North India.

\section{Literature Review}

As patients become more informed and healthcare providers increasingly mindful and sensitive about sharing inaccurate and deceived information about patients, EHR implementation is seen as a necessary albeit complex, safety-critical process (Institute of Medicine, 2012). In today's era of advancing e-health technologies, improvements in hospital operational efficiency and care outcomes cannot be fully achieved unless EHRs are adopted. The term "adoption" implies more than just simply using an EHR. In practice, 'adoption' commonly refers to uptake of a new technology by both individuals and organizations (Rogers, 2010). In the context of EHRs, adoption by physicians implies regular and sustained use of technology over a continuous period. Hence, the mere presence of an EHR in a hospital does not imply that physicians will use it regularly until these same physicians also adopt the technology (Williams, 1992). Owing to the failure to knowledge translate from past research and best practices achieved in developed countries, technological implementation such as that of an EHR in developing countries.

EHRs have been implemented by an ever increasing number of hospitals around the world (Abramson et al., 2011). But, the technical aspects of EHR implementation are complex and require skillful execution for its success. Failed implementations are costly. Indeed, not only can a failed installation of EHRs in a hospital amount to huge monetary loss (Moukheiber, 2013), but reputation and image of the organization in question may also suffer correspondingly. An implementation failure creates high risk by diverting capital, operating funds and human resources from productive use and by weakening the hospital's position in the marketplace (Moukheiber, 2013; Rosenthal, 2002). It is possible that implementation challenges and experiential learning gained by healthcare professionals working within the context of developed countries (e.g., the United States and Canada) cannot be easily knowledge translated (Or, Dohan, \& Tan, 2014). Accordingly, commonly observed failures in EHR implementation in less developed countries are reflective of, and possibly a result of, many things. These may include (a) the lack of know-how to reconcile difficult-to-change cultural habits, (b) the need for local adaption in health organizational work-style related practices, and (c) the differing sociopolitical environments (Or et al., 2014).

As implementation of such a technology is still fairly new in India and is limited to only major corporate hospitals, understanding success factors for implementation of this technology must be clearly studied. In this regard, this study represents one step in accumulating specific knowledge to aid beginners, especially those healthcare organizations that fall within the small (less than 500 beds) to medium-sized (500-1,000 beds) hospitals, in their EHR implementation efforts.

\section{EHR Implementation in India}

The government of India has been pushing healthcare stakeholders, such as doctors, hospitals, and insurance companies, to deploy various technologies for combating ever-increasing healthcare cost while having a simultaneous need to improve quality and accessibility of healthcare facilities (Malach \& Baumol, 2012; Coiera, Aarts \& Kulikowski, 2012). So far, it has been reported that ICT usage in healthcare domain appears to be promising (Christensen, Bohmer \& Kenagy, 2000). It has even gone a step further by accepting EHRs as an essential component of the country's healthcare system with the aim of working towards its maximum adoption among all stakeholders (Jha et al. 2008). As noted in the extant literature, successful implementation of ICTs is one of the most critical issues for hospitals today (Moon, 2007). Several specific CTIFs are purported to drive success of EHR 
implementation. The study discusses and identifies those CTIFs that are deemed to be most relevant to this particular study in more details later. Though, the concept and significance of EHRs had reached India almost a decade ago, EHR implementation and meaningful use have still to catch up (Bhattacharya, Ramachandran, \& Jha, 2012; Sood et al., 2008).

For Indian hospitals to stay cost-effective, efficient and competitive in their routine care delivery business, an urgent need exists to take necessary steps and make substantive changes in outdated business processes, more specifically, manual driven paper-based systems, that are still being practiced among India hospitals. This, in turn, implies evolving the entire information systems and networks infrastructure within India's hospitals, thereby resulting in deployment of appropriate and advancing ICT mechanisms, as a competitive advantage weapon for healthcare organizations in India (Verma \& Khandelwal, 2011).

\section{Job Characteristics and Job Satisfaction}

Job satisfaction is generally recognized as a multifaceted construct that includes employee feelings about variety of intrinsic and extrinsic job elements (Howard \& Frink, 1996; Wayne, 2006). Jha et. al., (2009) has described as an employee's general attitude toward the job, it is the extent to which people like (i.e., are satisfied with) or dislike (i.e., are dissatisfied with) their jobs. Betts (2000) has defined job satisfaction as a perception of job by the job holder, who determines its level of satisfaction based upon physiological and psychological need. For decades, organizational researchers have been intrigued by employee satisfaction with work. Job satisfaction describes how content an individual is with his or her job (Noor \& Rudzi, 2010). Gupta \& Joshi (2008) have concluded that job satisfaction is an important technique used to motivate employees to work harder. Gupta and Joshi said that job satisfaction is very important because an employee spends maximum of his or her time at work place. Employees have more positive perceptions about organization's products and services when they have achieved satisfaction in their job and are able to deliver a better service (Bontis, Richards \& Serenko, 2011).

Job characteristics depend upon the psychological state of employees, which includes various factors such as meaningfulness of work (task identity, task significance, and skill variety), responsibility for outcomes (autonomy), and knowledge of results (feedback). According to the job characteristics model (JCM; Hackman \& Oldham, 1980), job characteristics of an individual lead to his or her job satisfaction. However, there are various external factors, such as economic situation, mobility, motivation, training, family, and other opportunities influencing individual job satisfaction (Bajwa et al., 2010), but enjoyment of work is almost always most strongly correlated with job satisfactions. Interesting jobs that provide a platform for polishing clinical skill, enhancement of training standards, provision of autonomy and feedback, satisfy most health workers (Tonges, Rothstein, \& Carter, 1998).

The success of any organization depends upon collection of individuals, including leaders and subordinates, also their feeling toward their job. The workplace is more productive when people are happy with the work environment. It enhances decision making ability because happiness reduces stress and uncertainty. In addition, new customers get attracted to happy employees because these employees treat customers substantially better. Happy employees will have high level of job satisfaction because they feel comfortable with organization. Job satisfaction is generally referred to person feelings of satisfaction on the job, which acts as a motivation to work (Brief \& Weiss, 2002; Price, 2004; Robbins, 2005).

This study focused specifically on implementation stages, with its findings being aimed at providing insights to the impact of the most applicable CTIFs for a successful roll out of EHR technology. It 
may also help in providing satisfied physicians within the small and medium-sized hospitals in North India.

\section{Theoretical Framework}

Jaana, Ward, and Bahensky (2012) focused on implementation success and elaborate on the notion that implementation success is determined by system quality and acceptance through participation. To better understand ICT challenges specific to EHR implementation context of our study, a key question is this: What are the top-rated CTIFs impacting EHR implementation in North India hospitals? In India, we can safely assume that the primary gatekeepers of healthcare services delivery for EHR roll out and use in hospitals would be chiefly practicing and attending to patients. More generally, Safdari et al. (2015) noted that critical variables responsible for success (or failure) of technology implementation, including EHR implementation in healthcare organizations, include the following: top management support, strategic planning, project champion, training, teamwork, change management culture, effective communication, computer knowledge, software attributes, and testing and troubleshooting.

Variables relating to EHR and other technology implementation have been cited throughout the extant literature. Note that the importance of CTIFs is expected to vary from one hospital environment to another due to differences in processes and practices of various organizations. Given that such e-health technology implementation is typically conceived as a new project, which a hospital might not have previously experienced, it is important, then, that prior to launching an EHR, the hospital needs to understand and assess its own health informatics competencies such as the ability to use technology effectively, strength in maintenance, availability of information technology expertise on site and the organizational propensity to knowledge absorption and technological innovation (Sood et al., 2008). Seemingly, a long list of applicable variables may be extracted to study the adoption of emerging technologies for healthcare organizations. Yet, these variables must be limited by the context of the study to which they are to apply; in our case, given that the assumed "care gatekeepers" would be the practicing physicians. We therefore select to focus only on those most relevant and crucial variables (CTIFs) that would fully support physician endusers in terms of EHR use and behavioral changes anticipated throughout EHR implementation process (see Figure 1).

Apart from being informed via the CTIF-related literature, physician experts were engaged to help identify and validate what are believed to be the most relevant CTIFs for inclusion in the study instrument. All group-rated items scoring above the Cronbach's alpha value of 0.7 have been considered in terms of internal consistency (reliability) of the instrument. Confirmatory factor analysis has been used to highlight the validity of instrument while collinearity statistics were subsequently preformed to ascertain that no multicollinearity exists among independent variables (or CTIFs). 


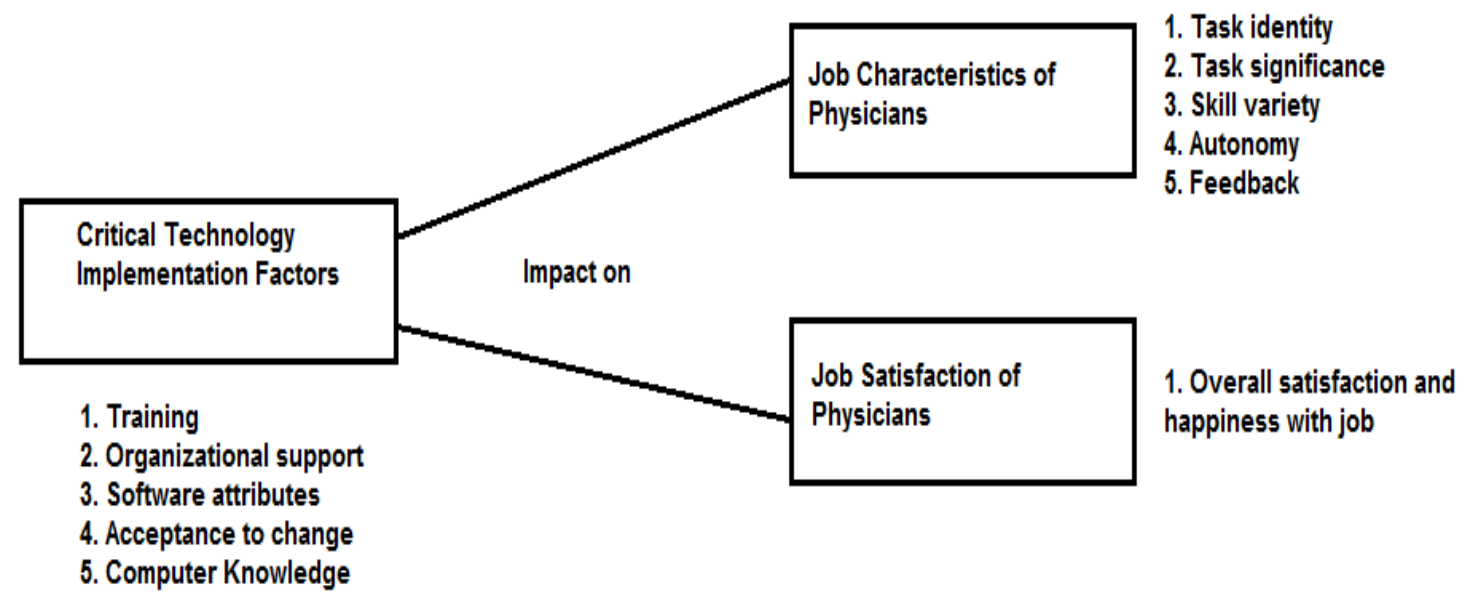

Figure 1. Theoretical Framework

\section{Methodology}

It was decided to use the survey methodology with physicians to be sampled as respondents. The motivation for enlisting physicians only, aside from ensuring homogeneity in the study population, helps limit the choice of CTIFs to be identified and included in the questionnaire instrument. A convenience sampling approach was subsequently employed. This was further justified by the homogeneity of the study population being sampled (physicians), the budgetary limit to conduct other forms of well-coordinated sampling such as a random survey, and the exploratory nature of the study, allowing the adoption of a preliminary type survey.

For the present study, both qualitative and quantitative information have been gathered through primary as well as secondary sources. Primary data has been collected from physicians of corporate hospitals using EHR technology through a pretested, structured and nondisguised questionnaire.

Questions have been formulated scale to study the impact of CTIFs of EHRs on job characteristics and job satisfaction. JCM (Hackman \& Oldham, 2005) has been used as the theoretical lens to study the job characteristics and job satisfaction of physicians. The JCM proposes a model of five "core" job characteristics (skill variety, task identity, task significance, autonomy, and feedback). JCM is extended by suggesting that EHR implementation moderates the relationships between job characteristics and job satisfaction. Eighteen statements have been used to represent job characteristics and satisfaction of the physicians using EHR technology. A construct based on statements representing critical technology implementation factors of EHRs in hospitals has been developed. It has been represented with five dimensions using 15 statements. Before starting data collection for the entire sample, a pilot study has been conducted on 100 physicians for testing the reliability and validity of various constructs used. It has helped in modifying the questionnaires usefully.

Analysis included 280 fully filled physician responses of out of a total of 350 questionnaires distributed to practicing physicians in 12 corporate multispecialty hospitals based in North India. Despite the use of a convenience sampling, the survey yields an $80 \%$ response rate after eliminating nonrespondents as well as those with incomplete (or inappropriate) responses; for example, those 
responses with all strongly disagree (or strongly agree) being marked for all questions. A 5-point Likert-type rating scale $(1=$ strongly disagree to $5=$ strongly agree $)$ has been used to measure all items. Population of this research study is very large and enumeration of all members is nearly impossible. On the basis of availability of physicians in multispecialty hospitals in different cities the respondents have been selected. Due care has been taken to include respondents from all age groups, educational levels, designations, work areas, and genders. This has helped in making the sample more representative of the population. No specific attempt has been made to focus on any particular healthcare service provider. The study has been conducted in a period of one year duration including hospitals from all regions of North India. Some of the limitations of study are that the exploratory nature of the present study, the scope was limited to multispecialty hospital in North India. Respondents were limited to practicing physicians and findings from convenience sampling can be bias and too narrowly focused. Owing to the use of the parsimonious theoretical framework, the study focuses on some CTIFs with no moderating factors.

With the convenience sampling method, the results may also not be representative with limited generalizability. As such, it may be possible to widen the scope of study geographically; increase sample size; randomize the sampling; and having the CTIFs being considered separately based upon the preimplementation and postimplementation phases.

As Figure 1 depicts, the study aims to test the relationship between independent variables (CTIFs) and two dependent variables (Job characteristics and job satisfaction). Importantly, as the questionnaire was personally administered (and explained) to physicians on filling it, it is believed that such a process of administering the instrument vastly reduced the number of unanswered (or suspicious) responses.

\section{Data Analysis and Results}

To summarize the data without losing any of the important information, exploratory factor analysis has been conducted. This tool extracts the critical technology implementation factors affecting EHR technology implementation in hospitals. Respondents have been asked to give responses to various statements affecting their technology acceptance levels on a 5-point Likert-type scale. Measures of sample adequacy such as Kaiser-Meyer-Olkin (KMO) and Bartlett's test of sphericity have shown that factor analysis can be applied.

The KMO value $>0.6$ can be considered as adequate (Kaiser, 1974). From Table 1, it can be seen that KMO value (0.819) has been found to be acceptable, and seems to be indicative of a data set considered to be highly desirable for factor analysis (Kim \& Mueller, 1978).

Table 1. Kaiser-Meyer-Olkin and Bartlett's Test of Sphericity

\begin{tabular}{lc}
\hline Test & Value \\
\hline Kaiser-Meyer-Olkin & 0.819 \\
Bartlett's test of sphericity & \\
Approximate $\chi^{2}$ & $28,347.230$ \\
$d f$ & 897 \\
$p$ & .000 \\
\hline
\end{tabular}

The most common method of factor analysis is the exploratory factor analysis and the most common method of factor rotation is the varimax rotation (Kim \& Mueller, 1978). Thus, the crucial factors affecting EHR technology implementation have been tested using principal component factor analysis with varimax rotation. Principal axis factoring with varimax rotation method has been used for extracting the factors. Statements with factor loadings greater than 0.40 have been considered. Factors with an eigenvalue of one or more have been extracted. All the factors have been given 
appropriate names according to the statements that have been loaded on these factors. Rotated factor matrix has been used for this purpose.

With principal component analysis, five factors have been extracted depending on eigenvalues and variance explained as shown in Table 2 . The factor structure has explained $69.08 \%$ of total variance, which exceeds the threshold level, that is, $60 \%$ commonly used in social sciences (Hair et al., 2006).

Table 2. Factors, Eigenvalues, and Variances Explained

\begin{tabular}{lccc}
\hline Factors & Eigenvalues & Variance Explained & Relative Importance \\
\hline Training & 5.154 & 17.487 & 1 \\
Organizational support & 4.765 & 15.512 & 2 \\
Software attributes & 4.206 & 12.977 & 3 \\
Acceptance to change & 3.503 & 10.764 & 4 \\
Computer knowledge & 3.021 & 8.342 & 5 \\
\hline
\end{tabular}

\section{Naming of Factors}

Training: This particular CTIF may be regarded as the learning process needed by physicians to handle technology, for example, how using the technology would allow them to reap intended benefits as envisioned by a software company that has designed EHRs to be implemented following its preimplementation and implementation phases (Leonard \& Sittig, 2007).

Organizational support: This CTIF entails the type of support or help provided by top management as well as co-workers of hospitals to physicians to aid them in accepting, adopting and adapting to the use of emerging technology in their work practices (Miller \& Sim, 2004).

Software attributes: This CTIF refers to attributes embedded as special features within EHR software, for example, easy-to-learn and easy-to-use graphical user interface, userfriendly logins, customized fail-safe and error-prevention back-tracking functions, intelligent keyword searches and timely data backups, report generation functionality, and more (Haughom, Kriz, \& McMillan, 2011).

Acceptance to change: Physicians, who initiated their practices in the last 20-25 years, may often find it difficult to change their routine recordkeeping habits as they might be not willing to accept changes to their normal workplace processes such as the use of manual driven paper-based records. This CTIF can be measured by the willingness of the responding physicians to "adopt" such a habitual change in their daily practices (Gagnon et al., 2009).

Computer knowledge: This CTIF is intended to measure the extent to which physicians as end-users will be well versed with computer hardware, software, the use of any database management system, internet connectivity and an ability to maintain and extract relevant files and records containing pertinent patient information. In India, physicians generally aged 50 and above often have difficulty with technology use because of their lack of basic computer knowledge (Safdari et al., 2015).

\section{Multiple Regression}

To study the association between CTIFs of EHRs, job characteristics, and job satisfaction of physicians of hospital, multiple regression analysis has been carried out. Five factors obtained from factor analysis have been taken as independent variables and job characteristics and job satisfaction 
as two dependent variables separately. The entered variables are significant at $5 \%$ level of significance.

\section{Regression Analysis for Impact of CTIFs on Job Characteristics}

In Table 3, $R=.480$ signifies correlation between job characteristics and those predicted by regression model. In terms of variability in job characteristics by the fitted model, this amounts to a proportion of $R^{2}=0.202$. The Durbin-Watson value, which tests the serial correlation between errors, is 1.870 . The value is close to 2 , so it proves that the residuals are uncorrelated (Field, 2005).

Table 3. Model Summary for Crucial Technology Implementation Factors and Job Characteristics

\begin{tabular}{lccccc}
\hline Model & $\boldsymbol{R}$ & $\boldsymbol{R}^{\mathbf{2}}$ & Adjusted $\boldsymbol{R}^{\mathbf{2}}$ & $\begin{array}{c}\boldsymbol{S} \boldsymbol{S} \text { of the } \\
\text { Estimate }\end{array}$ & Durbin-Watson \\
\hline 1 & $.480^{\mathrm{a}}$ & .206 & .202 & .70474 & 1.870 \\
\hline
\end{tabular}

a Predictors: (Constant), training, acceptance_to_change, computer_knowledge, organizational_support, software_attributes

From the analysis of variance (Table 4$)$, the value of $F(2,204)=38.431, p<0.05$ indicates that at least one of the five variables is strongly related to job characteristics.

Table 4. Analysis of Variance for Crucial Technology Implementation Factors and Job Characteristics

\begin{tabular}{lcrrrr}
\hline Model 1 & Sum of Squares & \multicolumn{1}{c}{$\boldsymbol{d} \boldsymbol{f}$} & Mean Square & $\boldsymbol{F}$ & $\boldsymbol{p}$ \\
\hline Regression & 42.732 & 2 & 25.542 & 38.431 & $.000^{\mathrm{a}}$ \\
Residual & 51.513 & 204 & .461 & & \\
Total & 94.245 & 206 & & & \\
\hline
\end{tabular}

a Predictors: (Constant), training, acceptance_to_change, computer_knowledge, organizational_support, software_attributes

The $\beta$ values (Table 5) tell to what degree each predictor affects the outcome. The $t$ test helps in measuring significant contribution of each and every predictor to the model. Training, acceptance to change, and organizational support $(p<.001$, significance $>.050)$ are not making significant contribution to the model. That means $t$ test associated with $\beta$ values of only this variable is insignificant. Computer knowledge and software attributes have been observed to be making significant contribution to the model.

Table 5. Coefficients of Crucial Technology Implementation Factors and Job Characteristics

\begin{tabular}{lccccc}
\hline & \multicolumn{2}{c}{$\begin{array}{c}\text { Unstandardized } \\
\text { Coefficients }\end{array}$} & $\begin{array}{c}\text { Standardized } \\
\text { Coefficient }\end{array}$ & & \\
\cline { 2 - 5 } Model 1 & $\mathbf{B}$ & SE & $\boldsymbol{\beta}$ & $\boldsymbol{t}$ & $\boldsymbol{p}$ \\
\hline (Constant) & 1.852 & .124 & & 12.185 & .000 \\
Training & 0.054 & .039 & .209 & 1.699 & .503 \\
Acceptance to change & 0.184 & .037 & .152 & 1.870 & .718 \\
Computer knowledge & 0.153 & .048 & .245 & 3.788 & .000 \\
Organizational support & 0.041 & .037 & .069 & 0.434 & .587 \\
Software attributes & & & & & .000 \\
\hline
\end{tabular}

Table 6 depicts the variance inflation factor (VIF), which measures the impact of collinearity among the variables in a regression model. Assumption of no multicollinearity stands true here because all the VIF values are well below 10 and the tolerance statistics are above 0.2 . Also, the average VIF is very close to 1 and it confirms that collinearity is not a problem for this model. 
Table 6. Collinearity Statistics for Crucial Technology Implementation Factors and Job

\section{Characteristics}

\begin{tabular}{lcc}
\hline Variable & Tolerance & Variance Inflation Factor \\
\hline Training & .468 & 1.761 \\
Acceptance to change & .685 & 0.995 \\
Computer knowledge & .780 & 1.558 \\
Organizational support & .403 & 1.987 \\
Software attributes & .304 & 0.785 \\
Training $\rightarrow$ Job characteristics & & Not supported \\
Acceptance to change $\rightarrow$ Job characteristics & & Not supported \\
Computer knowledge $\rightarrow$ Job characteristics & & Supported \\
Organizational support $\rightarrow$ Job characteristics & & Not supported \\
Software attributes $\rightarrow$ Job characteristics & & Supported \\
\hline
\end{tabular}

On the basis of regression model, computer knowledge and software attributes have significant impact on job characteristics of physicians.

\section{Regression Analysis for Impact of CTIFs on Job Satisfaction}

The $R$ of 0.717 signifies a strong correlation between job satisfaction and those predicted by regression model. In terms of variability in job satisfaction, this amounts to a large proportion of $R^{2}$ $=0.560$. The Durbin-Watson value, which tests the serial correlation between errors, is 2.003, close to 2 . This it proves that the residuals are uncorrelated (Field, 2005).

Table 7. Model Summary for Crucial Technology Implementation Factors and Job Satisfaction

\begin{tabular}{lccccc}
\hline Model & $\boldsymbol{R}$ & $\boldsymbol{R}^{\mathbf{2}}$ & Adjusted $\boldsymbol{R}^{\mathbf{2}}$ & $\begin{array}{c}\boldsymbol{S} \boldsymbol{E} \text { of the } \\
\text { Estimate }\end{array}$ & Durbin-Watson \\
\hline 1 & $.717^{\mathrm{a}}$ & .569 & .560 & .21924 & 2.003 \\
\hline
\end{tabular}

a Predictors: (Constant), training, acceptance_to_change, computer_knowledge, organizational_support, software_attributes

From the analysis of variance (Table 8 ), the value of $F(2,203)=65.619, p<.001$ indicates that at least one of the five variables is related to job satisfaction.

Table 8. Analysis of Variance for Crucial Technology Implementation Factors and Job Satisfaction

\begin{tabular}{lcrccc}
\hline Model 1 & Sum of Squares & \multicolumn{1}{c}{$\boldsymbol{d} \boldsymbol{f}$} & Mean Square & $\boldsymbol{F}$ & $\boldsymbol{p}$ \\
\hline Regression & 63.605 & 2 & 31.803 & 65.619 & $.000^{\mathrm{a}}$ \\
Residual & 98.385 & 203 & 0.485 & & \\
Total & 161.990 & 205 & & & \\
\hline
\end{tabular}

a Predictors: (Constant), training, acceptance_to_change, computer_knowledge, organizational_support, software_attributes

The $\beta$ values (Table 9) tell to what degree each predictor affects the outcome. Here, the $t$ test helps in measuring the significant contribution of each and every predictor to the model. Software attributes $(p<.001$, significance $>.050)$ is the only variable not making significant contribution to the model. That means the $t$ test associated with $\beta$ values of these variable is insignificant. 
Table 9. Coefficients for Crucial Technology Implementation Factors and Job Satisfaction

\begin{tabular}{lccccc}
\hline & \multicolumn{2}{c}{$\begin{array}{c}\text { Unstandardized } \\
\text { Coefficients }\end{array}$} & $\begin{array}{c}\text { Standardized } \\
\text { Coefficient }\end{array}$ & & \\
\cline { 2 - 4 } Model 1 & $\boldsymbol{B}$ & $\boldsymbol{S E}$ & $\boldsymbol{\beta}$ & $\boldsymbol{t}$ & $\boldsymbol{p}$ \\
\hline (Constant) & 1.452 & .194 & & 21.165 & .000 \\
Training & 1.454 & .231 & .439 & 1.699 & .000 \\
Acceptance to change & 0.084 & .031 & .182 & 1.870 & .003 \\
Computer knowledge & 0.253 & .049 & .145 & 3.788 & .007 \\
Organizational support & 0.044 & .047 & .349 & 0.434 & .000 \\
Software attributes & 1.353 & .048 & .245 & 3.788 & .518 \\
\hline
\end{tabular}

The VIF from Table 10 measures the impact of collinearity among the variables in a regression model. Assumption of no multicollinearity stands true here because all the VIF values are well below 10 and the tolerance statistics are above 0.2 . Also average VIF is very close to 1 and it confirms that collinearity is not a problem for this model.

Table 10. Collinearity Statistics for Crucial Technology Implementation Factors and Job Satisfaction

\begin{tabular}{lcc}
\hline Variable & Tolerance & Variance Inflation Factor \\
\hline Training & .468 & 1.761 \\
Acceptance to change & .685 & 0.995 \\
Computer knowledge & .780 & 1.558 \\
Organizational support & .403 & 1.987 \\
Software attributes & .304 & 0.785 \\
Training $\rightarrow$ Job satisfaction & & Supported \\
Acceptance to change $\rightarrow$ Job satisfaction & & Supported \\
Computer knowledge $\rightarrow$ Job satisfaction & & Supported \\
Organizational support $\rightarrow$ Job satisfaction & & Supported \\
Software attributes $\rightarrow$ Job satisfaction & & Not Supported \\
\hline
\end{tabular}

On the basis of regression model, factors having significant impact on job satisfaction of physicians are training, acceptance to change, computer knowledge, and organizational support.

\section{Supporting CTIFs on Physicians Job Characteristics and Job Satisfaction}

Altogether, even within the exploratory context of this study, the analytic results may be quite useful in providing insights into CTIFs for deploying EHRs for North India hospitals. Specifically, two CTIFs, computer knowledge and software attributes, have influential impact on job characteristics, whereas, training, acceptance to change, computer knowledge and organizational support have strongest impact on job satisfaction of physicians throughout EHR implementation including preimplementation preparation. The research, however, does not supplant or replace important work already done in this area. Instead, it intends to extend previous work on CTIFs in the direction of operational specificity for North India hospitals. While CTIFs are useful when expressed as a higher level strategic framework, they also take on additional utility to guide practitioners when expressed in more granular, task-focused terms. These factors should be carefully studied to aid hospitals and/or other healthcare organizations in successfully implementing EHR systems within specific environments. 


\section{Discussion}

India has a vibrant and rapidly growing population. The country faces many fresh challenges such as the idea of creating a national EHR system. Currently, India's healthcare system comprises both private and public hospitals. In spite of having a large number of public hospitals, many people opt for private hospitals due to the promise of better care, higher quality infrastructure, shorter wait times, and more medical equipment and supplies (as compared to public hospitals). Unless EHRs are widely and successfully, adopted throughout government health facilities, these organizations will continue to be overcrowded with long wait times and operational inefficiencies. EHR records, if implemented and adopted by physicians, can effectively help, among other processes, to reduce queuing during the registration phase as well as shortening the time and lowering the costs needed for the treatment of individual patients. For instance, a substantial expense of time and money can be saved in accessing diagnostic services related to past diagnostics and imaging that may have to be repeated for the same patients due to ineffective management of patient records.

\section{Conclusion}

At present, the EHR technology has been implemented in private multispecialty hospitals; if the same technology can be successfully implemented in the public sector, it is anticipated that patients being placed at the bottom of the pyramid can also be treated in better, faster and more effective manner. The Integrated National Health System was created and the government of India hopes to provide universal healthcare to all of its citizens by 2020. This vision is possible only if India moves successfully to achieving a strong integrated health information system.

As an "emerging" economy, India's progress in terms of EHR development will help it to create a system of standards that will promote interoperability and bolster the national system. The next step could be to diffuse adoption of EHR systems in urban as well as rural areas. This can be done by motivating physicians to accept the change from traditional paper-based records to electronic records, by providing organizational support and by ensuring that reputable vendors are engaged to provide quality EHR systems with great software attributes. As a member of International Health Terminology Standards Development Organization, India should also support affordable and consistent use of terminologies among healthcare providers through Systematized Nomenclature of Medicine Clinical terms. Apparently, this can be easily made possible nationwide with the promotion of EHRs and other ICTs implementation and adoption by physicians. Next, we highlight the study limitation and provide future research direction.

\section{Future Research}

Implementation and adoption of EHRs in Indian healthcare settings is a vast topic that involves multifaceted dimensions, including various types of users and subsettings. In future studies, other CTIFs as well as possible moderating factors may also be included to have a broader and more in depth analysis of empirical data to be collected. Comparisons across different hospital types, where EHR technology is implemented, can also be done. Users such as administrators, nurses and other healthcare professionals who use the same technology, but in a different perspective, can also be studied. Apart from private multispecialty hospitals, tertiary healthcare public hospitals using EHR technology, which serve a major part of the bottom-of-pyramid, can also be considered. In summary, the journey of EHRs begins with preimplementation preparation, then implementation of the technology, and continues with postimplementation. Thus, continued effort is needed after the EHR goes live to reap the full benefits of the system. The contribution expected from, and emphasis on, individual CTIFs may change dynamically to be able to ensure continued success of EHR use and to reduce the likelihood of technology failure during these three stages of an EHR life cycle. The results of our exploratory study showed that five CTIFs, namely, training, acceptance to change, 
organizational support, computer knowledge, and software attributes of EHRs, are critical to ensure success of an EHR implementation. How the different CTIFs impact on the different stages of an effective EHR implementation is also a key research question to be investigated by future researchers.

\section{References}

Abramson, E. L., McGinnis, S., Edwards, A., Maniccia, D. M., Moore, J., \& Kaushal, R. (2011). Electronic health record adoption and health information exchange among hospitals in New York State. Journal of Evaluating Clinical Practices, 18, 1156-1162.

Ajami, S., \& Bagheri-Tadi, T. (2013). Barriers for adopting electronic health records (EHRs) by physicians. Acta Informatics Medical, 21, 129-134. doi:10.5455/aim.2013.21.129-134

Bajwa, S. S., Virdi, S. S., Bajwa, S. K., Ghai, G. K., Singh, K., \& Rana, C. S. (2010). In depth analysis of motivational factors at work in the health industry. Industrial Psychiatry Journal, 19, 20 29.

Betts, P. W. (2000). Supervisory management (7th ed.). London, United Kingdom: Prentice Hall.

Bhattacharya, I., Ramachandran, A., \& Jha, B. (2012). Healthcare analytics on the cloud. Online Journal of Health and Allied Sciences, 11, 1-16.

Bontis, N., Richards, D., \& Serenko, A. (2011). Improving service delivery: Investigating the role of information sharing, job characteristics, and employee satisfaction. The Learning Organization, 18, 239-250.

Brief, A. P., \& Weiss, H. M. (2002). Organizational behavior: Affect in the workplace. Annual Review of Psychology, 53, 279-307.

Christensen, C. M., Bohmer, R., \& Kenagy, J. (2000). Will disruptive innovations cure health care? Harvard Business Review, 78, 102-112.

Coiera, E., Aarts, J., \& Kulikowski, C. (2012). The dangerous decade. Journal of the American Medical Informatics Association, 19, 2-5. doi:10.1136/amiajnl-2011-000674

Eni, G., \& Tan, J. (1989). Going north on a north-bound trail: A model for achieving health management goals and objectives. Health Services Management Research, 2, 146-154. doi:10.1177/095148488900200206

Field, A. (2005). Discovering statistics through SPSS. Thousand Oaks, CA: Sage.

Gagnon, M. P., Legare, F., Labrecque, M., Fremont, P., Pluye, P., \& Gravel, K. (2009). Interventions for promoting information and communication technologies adoption in healthcare professionals. Cochrane Database System Review, 1, CD006093. doi:10.1002/14651858.CD006093.pub2

Gupta, S. K., \& Joshi, R. (2008). Human resource management. Ludhiana, India: Kalyani.

Hackman, J. R., \& Oldham, G. R. (1980). Work redesign. Reading, MA: Addison-Wesley.

Hair, J. F., Black, W. C., Babin, B. J., Anderson, R. E., \& Tatham, R. L. (2006). Multivariate data analysis. Cranbury, NJ: Pearson Education.

Haughom J., Kriz, S., \& McMillan, D. R. (2011). Overcoming barriers to EHR adoption. Healthcare financial management. Journal of the Healthcare Financial Management Association, 65, 96100.

Howard, J. L., \& Frink, D. D. (1996). The effects of organizational restructure on employee satisfaction. Group and Organization Management, 21, 278-303. 
Institute of Medicine. (2012). Health IT and patient safety: Building safer systems for better care. Washington, DC: National Academy Press.

Jaana, M., Ward, M. M., \& Bahensky, J. A. (2012). EMRs and clinical IS implementation in hospitals: A statewide survey. Journal of Rural Health, 28, 34-43.

Jha, A. K., Bates, D. W., Jenter, C., Orav, E. J., Zheng, J., Cleary, P., \& Simon, S. R. (2009). Electronic health records: Use, barriers and satisfaction among physicians who care for Black and Hispanic patients. Journal of Evaluation in Clinical Practice, 15, 158-163. doi:10.1111/j.1365-2753.2008.00975.x

Jha, A. K., Doolan, D., Grandt, D., Scott, T., \& Bates, D. W. (2008). The use of health information technology in seven nations. International Journal of Medical Informatics, 77, 848-854. doi:10.1016/j.ijmedinf.2008.06.007

Kaiser, H. F. (1974). An index of factorial simplicity. Psychometrika, 39, 31-36.

Kaplan, B., \& Harris-Salamone, K. (2009). Health IT success and failure: Recommendations from literature and an AMIA workshop. Journal of the American Medical Informatics Association, 16, 291-299. doi:10.1197/jamia.M2997

Kim, J. O., \& Mueller, C. W. (1978). Introduction to factor analysis. What it is and how to do it. Beverly Hills, CA: Sage.

Malach, M., \& Baumol, W. J. (2012). Opportunities for cost reduction of medical care: Part 3. Journal of Community Health, 37, 888-896. doi:10.1007/s10900-011-9534-8

Miller, R. H., \& Sim, I. (2004). Physicians' use of electronic medical records: Barriers and solutions. Health Affairs, 23, 116-126.

Moon, Y. B. (2007). Enterprise resource planning (ERP): A review of the literature. International Journal of Management and Enterprise Development, 4, 235. doi:10.1504/IJMED.2007.012679

Moukheiber, R. (2013). The staggering cost of an epic electronic health record might not be worth it. Forbes, 24, 14-25.

Or, C., Dohan, M., \& Tan, J. (2014). Understanding critical barriers to implementing a clinical information system in a nursing home through the lens of a socio-technical perspective. Journal of Medical Systems, 38, 1-10. doi:10.1007/s10916-014-0099-9

Pare, G., Sicotte, C., \& Jacques, H. (2006). The effects of creating psychological ownership on physicians acceptance of clinical information systems. Journal of the American Medical Informatics Association, 13, 197-205. doi:10.1197/jamia.M1930

Price, J. L. (2004). The development of a causal model of voluntary turnover. In R. Griffeth \& P. Hom (Eds.), Innovative theory and empirical research on employee turnover (pp. 3-34). Greenwich, CT: Information Age.

Robbins, S. P. (2005). Organizational behavior (11th ed.). Upper Saddle River, NJ: Pearson Prentice Hall.

Rogers, E. M. (2010). Diffusion of Innovations. New York, NY: Simon and Schuster.

Rosenthal, D. A. (2002). Managing non-technical factors in healthcare IT projects. Journal of Healthcare Information Management, 16, 56.

Safdari, R., Ghazisaeidi, M., \& Jebraeily, M. (2015). Electronic health records: critical success factors in implementation. Acta Informatica Medica, 23, 102-104. doi:10.5455/aim.2015.23.102-104 
Simon, S. R., Keohane, C. A., Amato, M., Coffey, M., Cadet, M., \& Zimlichman, E. (2013). Lessons learned from implementation of computerized provider order entry in 5 community hospitals: A qualitative study. BMC Medical Informatics and Decision Making, 13, 67.

Sood, S. P., Nwabueze, S. N., Mbarika, V., Prakash, N., Chatterjee, S., Ray, P., \& Mishra, S. (2008). Electronic medical records: A review comparing the challenges in developed and developing countries. Journal of System Sciences, 35, 132-141.

Tonges, M. C., Rothstein, H., \& Carter, H. K. (1998). Sources of satisfaction in hospital nursing practice: A guide to effective job design. Journal of Nursing Administration, 28, 47-61.

Verma, D. S., \& Khandelwal, U. (2011). Consumers' preferences towards service industry: A factorial study of health care industry. International Journal of Multidisciplinary Research, 1, 83-89.

Ward, M. M., Vartak, S., Loes, J. L., O’Brien, J., Mills, T. R., Halbesleben, J. R. B., \& Wakefield, D. S. (2012). CAH staff perceptions of a clinical information system implementation. American Journal of Managed Care, 18, 244-252.

Wayne, F. C. (2006). Managing human resource: Productivity, quality of work life profits (7th ed.). New York, NY: McGraw-Hill.

Williams, L. S. (1992). Microchips versus stethoscopes: Calgary hospital, MDs face off over controversial computer system. Canadian Medical Association Journal, 147, 1534-1540.

The International Journal of Applied Management and Technology (IJAMT), sponsored by Walden University's School of Management, is a peer-reviewed, online journal that addresses contemporary national and international issues related to management and technology. The objectives of the IJAMT are to: (a) encourage collaborative and multi-disciplinary examinations of important issues in business and technology management, and (B) engage scholars and scholar-practitioners in a dynamic and important dialogue.

Walden University Publishing: http://www.publishing.waldenu.edu 